\title{
Notas sobre a mimese: para pensar o teatro contemporâneo
}

\section{Fernando Kinas}

\section{Resumo:}

Discussão sobre o conceito e a prática da mimese no teatro contemporâneo a partir de contribuições clássicas (Aristóteles, Diderot, Hegel) e recentes (Brecht, Abirached, Lehmann, Guénoun). O texto avança a hipótese de um reposicionamento do debate em torno da ficção teatral a partir de questionamentos radicais das últimas décadas, como a formulação de um teatro "pós-dramático".

\section{Palavras Chave:}

Teatro, mimese, pós-dramático.

\begin{abstract}
:
Discussion about the concept and practice of mimesis in contemporary theater from classic (Aristotle, Diderot, Hegel) to recent studies(Brecht, Abirached, Lehmann, Guénoun) studies. The text advances the hypothesis of a reposition about the debate on the theatrical fiction from radical questioning of recent decades, as the formulation of a "post-dramatic" theater.
\end{abstract}

\section{Keywords:}

Theater, mimesis, post-dramatic.

\section{"Nihil autem crescit sola imitatione" [Só pela imitação não há crescimento]. (Quintiliano)}

Não é fácil investigar um conceito tão complexo quanto o de mimese - ou mimesis -, ainda mais quando a intenção é de, a partir dele, identificar alguns dos novos contornos assumidos pelo teatro contemporâneo. Se à alteração de conceitos como ficção, ação e representação teatrais corresponde uma igual alteração (rarefação ou reconfiguração) destes fenômenos nas práticas teatrais a partir de meados do século vinte, cabe fazer um esforço analítico de reconstrução conceitual capaz de alimentar novas formas de compreensão e, eventualmente, de intervenção no panorama teatral. De Aristóteles à Denis Guénoun, passando por Hegel e Robert Abirached, o presente texto esboça algumas ideias sobre o tema da mimese para pensar criticamente o teatro atual.

Se é sabido que entre os antigos não havia uniformidade a respeito da noção de mimese, não é menos sabido que as traduções para "imitação" nas modernas línguas européias, entre elas o português, serviu para obscurecer diferentes abordagens sobre um, aparente, tema único. Com o exemplo das três camas (a ideal, a do artesão e a do pintor), Platão no livro X da República põe a mimese em conflito com o mundo idealista dos "arquétipos". E o imitador, "criador de fantasmas" (PLATÃO, 2006: X, 601b), como sabemos, goza de muito pouco prestígio nesta república. Em Aristóteles a "imitação" já é de outra natureza. R. M. Rosado Fernandes resume assim a questão: "Naturalmente que o imitar não significa aqui copiar, mas sim fazer como ou fazer como a natureza faz, na medida em que o verbo mimeisthai que inegavavelmente significa imitar, nem sempre pode ser traduzido como tal" (ROSADO FERNANDES, 1986: 15). Ou seja, "a cópia não é [necessariamente] servil", ela afasta-se da idéia pejorativa de "plágio". O próprio Aristóteles deixa clara a questão ao afirmar que a imitação do poeta poderá incidir sobre as coisas não apenas como elas são, mas também "como deveriam ser" (ARISTÓTELES, 1992: 1460b, 11). 
Com o tempo aumentaram as sutilezas semânticas e os usos concretos da noção de mimese pelos poetas e investigadores do tema. No período helenístico e romano, por exemplo, Longino, Horácio, Cícero, Quintiliano (que forneceu a epígrafe deste trabalho), Luciano e Dionísio de Halicarnasso são alguns destes autores. Assim, as reflexões, comentários e tratados sobre a mimese fornecem matéria-prima para se pensar a evolução do teatro, culminando com os questionamentos radicais das últimas três ou quatro décadas.

Não há dúvida que a tradição aristotélica se impôs sobre a platônica, e a mimese "positiva" de Aristóteles transformou-se em referência para as práticas e para as investigações artísticas. Entretanto, num momento preciso da história, uma oposição contundente, de viés platônico, marcou uma nova etapa na discussão da mimese. Hegel recusa a "imitação", fazendo a distinção entre obras de arte e artefatos técnicos. Estes últimos seriam produzidos a partir da imitação. Àquelas, originadas de um processo mais complexo, não poderiam surgir a partir da "cópia da natureza" (pois é assim que Hegel, retomando Platão, interpreta a noção de mimesis). Em uma aproximação entre Hegel e Heidegger, Victor Knoll lembra que para este último "a arte é o pôr-se-em-obra-da-verdade", portanto conviria à verdade a adaequatio e a homoiosis, substituindo a mimesis. A idéia de imitação, tal como a tradição aristotélica havia fixado, estaria assim descartada, ou ao menos suplantada pela ideia de criação, capaz de operar a "desocultação" das verdades (KNOLL, 1996: 63; 72).

Pela presença determinante que exerceu na reflexão artística, situado entre o mundo antigo e a contemporaneidade, vale aprofundar as contribuições de Hegel sobre a questão. Se admitimos que Hegel elaborou a sua estética utilizando o conceito-chave de 'Ideal', o conflito está posto entre o sensível e a idéia. A infinitude do espírito colide com a finitude do material. "O Ideal se define como manifestação sensível da Ideia" (idem, 1996: 64). A arte ideal surge, então, como expressão da razão, histórica, encarnada.

A dança hegeliana entre a história e a metafísica, ou entre a natureza e a idealidade, representa uma virada conceitual importante. "No lugar da imitação, diz Knoll, Hegel põe a construção, a invenção, o trabalho do espírito prático" (idem, 1996: 65). Ao substituir o belo pelo ideal, além de acrescentar noções como a de comunidade, Hegel revê o conceito aristotélico de mimesis, uma vez que não é mais possível, sob a perspectiva hegeliana, afirmar que a obra de arte é mimesis da physis. Se em Platão existia a dialética entre essência e aparência, entre o mundo inteligível e o mundo sensível, estas oposições estão ausentes em Aristóteles. Victor Knoll resume assim a operação aristotélica: "A mimesis tem como material (objeto) a história, que converte em fábula por força da techné segundo a maneira da physis (natureza)" (Id.:, 1996: 65). A tragédia, portanto, imita à moda da natureza, e não imita $a$ natureza!

A imitação, em Hegel, é então a imitação da idéia, mas como um processo que se desenrola na história (comunidade, caráter nacional etc.). Em relação ao mundo platônico, Hegel opera em uma espécie de "morde e assopra dialético". A physis aristotélica atende no modelo hegeliano pelo nome de razão. No entanto, ao nos movermos no terreno idealista, supondo que a arte manifesta o verdadeiro, não há saída analítica possível senão identificar "manifestação do verdadeiro" com "imitação da physis". O que seria, evidentemente, muito limitado, a não ser que entendamos a verdade como construção histórica provisória e a imitação como poder instaurador (e não como cópia ou simulacro) que funcionaria à maneira desta verdade historicizada.

Ao recusar a ideia de imitação como cópia, como faz Hegel na sua Estética, não nos aliamos tampouco, automaticamente, com a posição de uma imitação da Ideia. A hipótese, em Victor Knoll e outros hegelianos, é de que o conceito de mimesis, identificado com o conceito de ideal, "pode ser, então, reposto como fundamento da obra de arte" (Id.:, 1996: 77). Não parece suficiente evitar algo do platonismo - já que a imitação, no sentido hegeliano, aproxima-se da verdade, diferentemente do que admitia o pensamento platônico -, para que se possa salvar esta concepção de mimese quando aplicada ao teatro contemporâneo.

Em 1978, Robert Abirached publicou A crise da personagem no teatro moderno. O texto faz o inventário desta figura no mundo teatral ocidental, especialmente a partir do século dezenove, dramaturgia e encenação 
confundidas. E é através da análise das transformações da mimese (1) que o autor examina o fenômeno teatral. Abirached inicia afirmando que o "surgimento progressivo da burguesia, longe de arruinar a idéia de imitação nas artes e singularmente no teatro, leva, à primeira vista, a reforçá-la definitivamente", mas não sem perverter a noção aristotélica. A mimesis, diz ele, se esvazia do seu sentido primeiro e "contribui positivamente para perpetuar a inadequação da cena ao mundo" (ABIRACHED, 1978: 12). Este fenômeno progride, e na virada do século dezenove é a própria noção de representação que, também ela, entra em crise. A validade da mimesis e a validade do próprio teatro são colocadas em questão por um movimento natural de resposta à um mundo explodido, cujas referências tradicionais perdem força e nitidez. Em duas levas, a primeira entre os anos 1880 e 1925, a segunda nos anos cinqüenta, o teatro ensaia respostas às novas configurações do mundo. Craig, Brecht e Artaud resumem, para o autor, as principais tentativas que abalam os fundamentos do teatro, incluindo aí a noção de mimese, tal como definida pelo cânone clássico.

Para o abade d'Aubignac, a tragédia - mas a frase, segundo Abirached, valeria para todo o teatro - é um poema "chamado de drama, ou seja, ação, e não discurso; aqueles que representam se chamam atores, e não oradores; aqueles que estão presentes se chamam espectadores ou regardans [uso no original], e não ouvintes. Enfim, o lugar que serve para suas representações é chamado teatro, e não auditório, ou seja, um lugar de onde se olha o que se faz, e não onde se escuta o que se diz. Também é verdade que os Discursos que se fazem nele devem ser como as Ações daqueles que lá aparecem" (ABADE D'AUBIGNAC apud ABIRACHED, 1978: 53). Aí está definido o funcionamento, e a originalidade, da mimese teatral segundo o pensamento do classicismo francês do século dezessete. Existe um persistente consenso em torno desta definição, o objetivo da representação, pelo menos até o século dezoito é o de "imitar as ações dos homens", utilizando atores num espaço e tempo figurados, diante de um público convidado a acreditar (suspensão da incredulidade, inverossímil, crível, disposição tácita ao jogo etc.) nas imagens assim construídas (ABIRACHED, 1978: 89). Este consenso caduca, e o abalo, se no início está relacionado às prescrições absurdas, tais como a regra das três unidades, separação de gêneros, bienséance, mais tarde se espalha aos próprios fundamentos do sistema aristotélico. A cultura burguesa, cujo ponto de inflexão é a Revolução Francesa, altera a percepção do mundo. O novo espírito do tempo, necessariamente, renova a idéia, a prática e os pressupostos teatrais.

Diderot tem papel protagonista nessas transformações do panorama teatral. Para Abirached ele remaneja "o alcance e o sentido de vários termos chaves do dispositivo da mimese" (idem, 1978: 100), embora o alcance destas reformulações, segundo o autor, tenha sido mitigado pelas práticas teatrais subsequientes. Se "o teatro é o tableau fiel do que se passa no mundo" (BEAUMARCHAIS apud ABIRACHED, 1978: 101), qual a distância tolerável entre o mundo e o teatro? Em outras palavras, qual é a interferência da imitação nesse jogo entre o real e o ficcional? O processo mimético, dependendo da distância que provocaria entre os elementos deste binômio, corromperia, mutilaria ou empobreceria a revelação da verdade? Levando em conta que para Diderot existe, segundo Abirached, analogia entre a verdade e a ficção, a resposta parece ser positiva, ou seja, há uma perda neste caminho do real à ficção. Seria algo como ter que escrever, aventa Abirached, "um novo Misantropo a cada cinqüenta anos, porque não é mais a misantropia nela mesma que é interessante, mas por que e como ela se afirma, sob o império das circunstâncias locais, históricas, econômicas e sociais" (ABIRACHED, 1978: 105). O processo mimético proposto por Molière ficaria caduco quando inserido em um momento histórico diferente daquele em que foi escrito, assim como caducariam encenações (englobando todos os seus componentes: cenário, figurino, iluminação, estilo de interpretação etc.) que não levassem em conta os novos dados do seu tempo.

Em relação à mimese aristotélica, o teatro burguês nascente toma suas distâncias. "Entrando na era burguesa o teatro quer, cada vez mais, dissimular sua natureza teatral, que reivindicava a mimese aristotélica e que sublinhava todos os modos de interpretação que ela suscitou na sua história, da máscara antiga à declamação das tragédias do século dezessete" (Ibid.:, 108). Abirached lembra que, afinal de contas, foi Diderot que "inventou" a quarta parede e propôs o abandono da estilização, recusando, por exemplo, os coups de théâtre(2). Assim, Diderot respeita, de forma geral, a mimese aristotélica, ao mesmo tempo em que a "desvia de seus 
objetivos", pervertendo-a do interior. O papel cívico que ele destina ao teatro seria o responsável por essa nova configuração da mimese, que recusaria a estética do espelho. Estaria em jogo a capacidade da sociedade burguesa reativar "as virtudes da mimese teatral para outros fins que seu divertimento ou sua autocelebração" (Ibid.:, 1978: 109, 134).

De impacto inegável na revisão do edifício teatral moderno foi o descrédito lançado sobre a mimese aristotélica no último quarto do século dezenove, que teve como um dos marcos a publicação do Nascimento da tragédia, de Nietzsche, em 1872. De forma virulenta, o livro ataca os pressupostos teatrais vigentes nos últimos vinte séculos!, reivindicando uma restauração que se livraria da herança aristotélica e euripidiana. Jacó Guinsburg cita os quatro pecados capitais que Nietzsche identifica no autor d'As troianas: a épica desmitificada, o realismo mimético, o socratismo crítico e o otimismo cientificista (3).

Maeterlinck e os demais simbolistas, muitos dos expressionistas, o sonho strindberguiano, Jarry, Pirandello, entre outros, certamente também contribuíram para a desestabilização do alicerce mimético clássico, senão por outros motivos, ao menos pela recusa do modelo usual de dramaturgia ilusionista. Mas é Gordon Craig que se insurge de maneira incisiva contra a mimese aristotélica. É possível supor que, em função do recorte semântico que se aplique ao termo mimese, Craig estaria apenas reconfigurando a noção de Aristóteles. Mas esta postura significaria, potencialmente, atribuir a qualquer conceito um valor universal e imutável, uma vez que todo questionamento sempre poderia ser absorvido como mera readequação, recontextualização, reordenação, enfim, como simples ajustes em um modelo cuja validade não poderia, globalmente, ser posta em causa. Para evitar atitudes como a de Procusto, que adaptava os viajantes que lhe caíam à mão ao tamanho do seu leito de ferro, esticando-lhes ou cortando-lhes as pernas, seria conveniente investigar se o conceito de mimese, de tão encolhido ou esgarçado, ainda manteria sua pertinência, ou se, ao contrário, o mais indicado seria reconhecer uma efetiva mudança de paradigma, uma alteração qualitativa e substancial das práticas, levando à elaboração de uma nova ordenação conceitual.

Mas voltemos à Gordon Craig, que, segundo Abirached, empenha-se em demonstrar "a possibilidade de subtrair a cena ocidental do jugo da mimese aristotélica" (Ibid.:, 1978: 201). A radicalização das suas proposições (muitas até hoje ainda não devidamente exercitadas), culmina com a abolição das personagens e, logo, dos seres vivos que as incarnavam. Pergunta-se: é ainda pertinente falar em mimese/imitação/representação quando não existe mais, em cena, aquele que mimetiza/imita/representa? Formas e cores, abstrações geometrizantes, sons e linhas são capazes de "imitar ações", como prevê o capítulo VI da Poética? Se não há quem desempenhe o papel de suporte da fábula e da mimesis, o que restará destas duas grandes damas do teatro ocidental?

\section{Um novo ator}

Se no século dezoito a burguesia tomou consciência da sua força de mudança, de meados do século dezenove para diante um novo ator social, o proletariado descobre-se também como força coletiva de mudança. Brecht dá expressão teatral à essa nova realidade, revendo a moldura aristotélica que enquadrava o teatro europeu. Não se trata mais de simples gestão do modelo, nem de respostas pontuais ao mal-estar criado pelo teatro existente. Trata-se agora de fazer uma crítica radical. Aqui Brecht se aproxima de Meierhold (não aquele dos Teatros Imperiais, mas dos anos da biomecânica) e se distancia de Piscator (que ao subordinar o estético ao político descuida da formulação de alternativas poéticas mais elaboradas). Artaud, por outros caminhos, aponta na mesma direção: "Não é possível continuar a prostituir a idéia de teatro" (ARTAUD, 1985: 114).

Abirached, analisando a contribuição de Brecht, resume assim a questão:

O único meio que resta para desbloquear as engrenagens emperradas da mimese, restituindo-lhe uma ação sobre o mundo, é de submeter à uma dúvida sistemática todos os elementos constitutivos e todas 
as referências ordinárias da representação, interrogando-se novamente sobre a natureza do real e do teatral hoje em dia, reavaliando a relação da sensibilidade e da cultura modernas com o aristotelismo, estudando as estruturas dos diversos públicos de teatro e suas capacidades de adaptação, resignando-se, enfim, a aceitar esta verdade evidente que a Europa se encontra em uma encruzilhada, um pé no passado e outro mais ou menos engajado no futuro. É para estabelecer uma teoria geral da representação, com o cuidado de remodelá-la constantemente à luz de uma infatigável atividade cênica, que vai se dedicar Bertolt Brecht: não importa o que se pense dos seus pressupostos filosóficos e políticos ou dos resultados que ele obteve, deve-se reconhecer a singularidade e a ambição da sua empreitada, que, sem dúvida, não teve precedente desde Diderot (ABIRACHED, 1978: 261).

O que está em jogo é a definição de realidade e a(s) forma(s) de reproduzi-la artisticamente. Mas ao desfazer os equívocos sobre a refutação que Brecht fazia do aristotelismo (Brecht não se opunha à fábula; sua teatralidade afirmada não contradizia a Poética; o lugar ocupado pelo prazer antes os aproximavam do que os distanciavam etc.), sobra, entre outros aspectos, a recusa do teatro "culinário" e da relação passiva do públicoconsumidor diante da obra teatral fechada. É razoável pensar a revolução brechtiana não como uma política de terra arrasada, fazendo tabula rasa do aristotelismo, mas como um esforço de "submeter o teatro aristotélico a um trabalho dialético e a transformá-lo por este próprio movimento" (Ibid.:, 1978: 275).

Ao elaborar sua reflexão sobre a arte dramática oriental (5), Brecht deixou patente "seus esforços visando uma arte dramática não aristotélica", buscando aí "testemunhos e aliados no seu combate contra a estética burguesa da intemporalidade, contra o teatro culinário, contra Aristóteles" (MAYER, 1977: 120-124). Note-se aí o termo "intemporalidade". Neste novo dispositivo não há espaço para qualquer necessidade transcendente, característica da tragédia.

Evidentemente a problemática da distinção entre narrativo e dramático ganha, com Brecht, um novo estatuto. O modelo agora é o da testemunha de um acidente de rua, figura popular que transita livremente entre a narração e o reviver, entre a explicação e a sensação, entre a demonstração e a interpretação, entre o reconhecimento racional e a identificação emocional. Para que este sistema funcione, o distanciamento passa a substituir a "intervenção do imaginário" tal como proposto pela mimese aristotélica. Seria algo como um assalto à mimese, surpreendendo-a em plena ação e, assim, causando a suspensão dos seus efeitos. Uma mimese que se revela enquanto mimese não pode mais ser mimese, ou ainda, já não pode mais operar como mimese. Uma noção possível, que mereceria investigação suplementar, é a de "mimese produtiva", processo pelo qual nada seria imitado ou representado pelos atores (no sentido de acontecer em cena novamente), mas no qual uma realidade mutável poderia ser investigada (pelo público). Ao propor outras funções à mimese, afastando-a da mera idéia de representação, Brecht deixa-a por um fio.

Denis Guénoun reconhece que um problema dos nossos dias (ele escreve em 1999) é a desconfiança em relação à capacidade representativa dos textos dramáticos (desconfiança que pode ser estendida ao fenômeno teatral como um todo). Diz ele: "O que nas décadas recentes foi colocado em dúvida, quanto ao teatro, é sua aptidão para representar. Seja porque ele é considerado não habilitado, não hábil, realmente mal equipado e desajeitado em relação à representação, seja porque, de fato, [...] supõe-se que ele não a queira mais, a representação, que ele a recuse e a condene, e se faça o arauto da sua deposição". E logo adiante: "Teatro do ato de jogar [jouer], da presentação viva [à vif], de encenação do próprio teatro. Teatro que se despreende dos artifícios e do encantamento, teatro anti-mágico (anti-mago e anti-imagem, reticente aos magos e às imagens), teatro da lucidez, do prazer do pensamento e do sensível, mas afastado da sua irrealidade, das suas miragens e também da sua impotência" (GUÉNOUN, 2005: 29). Este teatro, que desconfia dos ídolos (eidolon), não deixa espaço para a mimese clássica, e talvez para mimese alguma.

A desafecção do drama, relacionada diretamente à recusa do caráter "total" do drama (sua estrutura fechada) e à coerência dramática (ações encadeadas, finalidade e, mesmo, destino, mesmo que não no sentido grego 
clássico), acompanhada da recusa dos pressupostos clássicos da experiência teatral são, ao mesmo tempo, resumidos e colocados em perspectiva por Guénoun em uma derradeira nota de pé de página, num texto mais recente:

Uma questão restaria à examinar com cuidado [...]: a de uma via de renovação do teatro, que se nutriria do reinvestimento da cena como prática, e não como lugar de representação. É o que procuraram os praticantes que quiseram justificar o jogo [jeu] não pela sua recepção na sala, mas pelo seu exercício mesmo: o Brecht das peças didáticas, concebidas para a encenação para os próprios atores, o Grotovski das pesquisas sem público etc. [...] Não para reservar o uso do teatro à uma elite de praticantes gozando de seu privilégio cênico, mas ao contrário na perspectiva de uma democratização dos prazeres do jogo, com o horizonte, utópico sem dúvida, de presentações públicas que valeriam mais como compartilhamento [partage] do que como espetáculo. Uma festa. Resta que este reengajamento cênico da praxis, pós-dramático certamente, valeria como descoberta inesperada com o fazer, positivamente assumido, e não somente com o desfazer e suas inclinações negativistas (Ibid.:, 2005: 199, nota 30).

O pós-dramático seria, como se pode vislumbrar, o algoz da mimese. E não apenas no sentido aristotélico, mas nas acepções mais contemporâneos que o termo vem admitindo. A situação pode ser traduzida como um progressivo declínio da ficção no teatro contemporâneo. Em oposição ao esquema clássico da divisão entre realidade e representação, Hans-Thies Lehmann mostra como a irrupção do real na cena desestrutura o modelo baseado na mediação ficcional. A despeito de uma recepção, sobretudo francesa, que relaciona o pós-dramático à recusa do primado do texto, as análises de Lehmann apontam para uma desficcionalização, e portanto, de crise da mimese, de caráter muito mais geral, apontando um novo paradigma para o fenômeno teatral, em que a idéia de interrupção (5), intervindo nos processos clássicos de fabricação teatral, destrona uma espécie de totalização autoritária, pilar do teatro dramático. No teatro pós-dramático existe a exigência de uma percepção aberta, fragmentada, distinta da abordagem uniformizante, globalizadora e sustentada nos processos miméticos clássicos. O teatro pós-dramático seria, então, mais presença do que representação; mais experiência compartilhada do que transmitida; mais processo do que resultado; mais manifestação do que significação (6).

$\mathrm{Na}$ consciência geral, segundo Lehmann, é verdade que a nova prática teatral se declara freqüentemente por uma distância polêmica em relação às coisas estabelecidas, despertando assim a impressão de dever sua identidade às normas clássicas" (LEHMANN, 2002: 37). Acreditar que o novo surja apenas da revisão do já conhecido, da requentada comida cotidiana, seria uma visão conservadora que parece ir além do conveniente, paralisando a crítica produtiva.

\section{Pequeno retorno a Iena (à guisa de encerramento)}

"A obra de arte ao ser reconhecida como um equilíbrio entre o sensível (manifestação) e a significação (Ideia), significação que se dá no e pelo sensível - como quer Hegel -, implica a consideração de que o sensível deve ser transformado de seu estado "bruto" para o estado espiritual; o sensível passa a ser uma voz que diz algo acerca do mundo" (KNOLL, 1996: 78). Ora, esta ideia de transformação, de passagem, e então, de representação, que Knoll aproxima da noção de mimesis aristotélica, foram colocadas em xeque pelo teatro contemporâneo. Mireille Losco e Catherine Naugrette afirmam que "o problema da representação em arte se origina no século vinte com a crise da mimesis, ou seja, coloca-se em questão a relação mimética da obra artística com o real" (7), reportando-se à poética aristotélica durante mais de vinte séculos, a arte dramática se definiu como uma prática "comandada" por esta categoria, no entanto, passado o ápice do realismo e das dramaturgias naturalistas, "as estéticas do século vinte rejeitam a idéia de uma relação mimética com o mundo" (LOSCO \& NAUGRETTE, 2005: 122). Esta crise, sem precedentes do ponto de vista histórico, revelaria o "desabamento do real e a confusão dos limites entre o eu e o mundo", a refutação radical da identificação, da catharsis e de procedimentos miméticos aristotélicos, contestam não apenas "as interpretações clássicas e 
neoclássicas (hegelianas) da poética aristotélica" (idem, 2005: 122) como muitas das tentativas, teóricas e práticas, para restaurar a validade da mimese no teatro contemporâneo.

\section{Bibliografia:}

ABIRACHED, Robert. La crise du personnage dans le théâtre moderne. Paris: Grasset, 1978.

ARISTÓTELES. Poética. Lisboa: Imprensa Nacional, 1992.

ARTAUD, Antonin. O teatro e seu duplo. São Paulo: Max Limonad, 1985.

BRECHT, Bertolt. Écrits sur le théâtre. Vol. 1. Paris: L'Arche, 1967.

DIDEROT, Denis. Discurso sobre a poesia dramática. São Paulo: Brasiliense, 1986.

DIONÍSIO DE HALICARNASSO. Tratado da imitação. Lisboa: Instituto Nacional de Investigação Científica, 1986.

GUÉNOUN, Denis. Actions et acteurs - Raisons du drame sur scène. Belin, 2005.

GUINSBURG, Jacob. "Nietzsche no teatro". In: O nascimento da tragédia. São Paulo: Companhia das Letras, 2006.

HEGEL, G. W. F. Cursos de estética I. São Paulo: Edusp, 1999.

. Cursos de estética IV. São Paulo: Edusp, 2004.

KNOLL, Victor. "Sobre a questão da mimesis". Discurso - Revista do Departamento de Filosofia da USP, número 27, 1996.

LEHMANN, Hans-Thies. Le théâtre postdramatique. Paris: L'Arche, 2002.

. Teatro pós-dramático e teatro político. Revista Sala Preta, número 3, 2003.

LOSCO, Mireille \& NAUGRETTE, Catherine. "Mimèsis (crise de la)". In: Lexique du drame moderne et contemporain. Belval: Circé, 2005.

MAYER, Hans. Brecht et la tradition. Paris: L'Arche, 1977.

PLATÃO. A República. São Paulo: Perspectiva, 2006.

\section{Notas:}

Este texto é o resumo de um trabalho escrito para a disciplina Mimese, estética e a cena contemporânea, ministrada por Luiz Fernando Ramos na Escola de Comunicação e Artes da Universidade de São Paulo, no segundo semestre de 2006. 
(1) "Por mimese, diz o autor, eu não entendo somente a representação e a imitação da realidade, mas um conjunto de protocolos que regem o exercício do teatro" In: ABIRACHED, Robert. La crise du personnage dans le théâtre moderne. Paris: Grasset, 1978, p. 451, nota 2.

(2) Cf. DIDEROT, Denis. Discurso sobre a poesia dramática. São Paulo: Brasiliense, 1986, cap. 11.

(3) Cf. GUINSBURG, Jacó. "Nietzsche no teatro". In: O nascimento da tragédia. São Paulo: Companhia das Letras, 2006, p. 163.

(4) Cf. BRECHT, Bertolt. "Notas sobre a arte dramática chinesa", de 1938, ampliadas mais tarde no capítulo "Efeitos de distanciamento na arte dramática chinesa". In: BRECHT, Bertolt. Écrits sur le théâtre. Vol. 1. Paris: L'Arche, 1967.

(5) "Como podemos, numa sociedade como a em que vivemos hoje, de mídia e de massa, criar através do teatro essa situação de interrupção?" (Cf. LEHMANN, Hans-Thies. "Teatro pós-dramático e teatro político". In: Revista Sala Preta, número 3, 2003, p. 11).

(6) Cf. LEHMANN, Hans-Thies. Le théâtre postdramatique. Paris: L'Arche, 2002. Esta obra, embora algo generalista, transformou-se em referência para a reflexão sobre as novas configurações do teatro contemporâneo.

(7) LOSCO, Mireille \& NAUGRETTE, Catherine. Lexique du drame moderne et contemporain. Belval: Circé, 2005, p. 118. Este "léxico", organizado por Jean-Pierre Sarrazac, é um esforço de sistematização sobre a crise do drama à partir da obra clássica de Peter Szondi Teoria do drama moderno (1954).

\section{Mini Currículo :}

Doutorando em teatro (Sorbonne Nouvelle, Paris 3 e ECA-USP), mestre em teatro e artes do espetáculo (Sorbonne Nouvelle, Paris 3), diretor e pesquisador teatral. 